\title{
Research Status and Prospect of Ceramic Membrane
}

\author{
Wei SUN ${ }^{1, a}$,Shoubin ZHANG ${ }^{1, b^{*}}$, Huajun SUN ${ }^{2, c}$ \\ ${ }^{1}$ School of Civil Engineering \& Architecture, University of Jinan, NO.336, Nanxinzhuang West Road., \\ Jinan 250022, P.R.China \\ ${ }^{2}$ Advanced Ceramic Institute, Zibo New \& Hi-tech Industrial Development Zone, Zibo 255000, \\ P.R.China

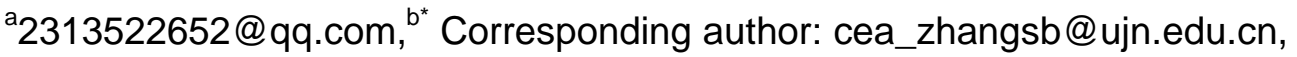 \\ c174051406@qq.com
}

\begin{abstract}
Keywords: Membrane separation technology; ceramic membrane; Development status; Prospect. Abstract. In recent years, science and technology change with each passing day, people's impacts on the natural environment are growing, too. Because of its high separation efficiency, simple operation, and so on, membrane separation technology is applicate by the worldwide. In the membrane separation technology, because of inorganic ceramic membrane's better performance it comes to the fore, inorganic ceramic membrane with high temperature, chemical stability, mechanical strength and other characteristics of its wide range of applications in various fields. Based on the research of inorganic ceramic membrane separation technology, this paper summarizes the development of inorganic ceramic membrane and this paper prospects for inorganic ceramic membrane's development of future. It also provides some references for the expansion of ceramic membrane in water treatment.
\end{abstract}

\section{Introduction}

Membrane separation technology is a separation technology, it developed gradually in the 20th century, 60 years .Because of separate high efficiency, easy operation, energy saving and environmental protection, the separation technology has been widespread concern by the community. Since the 1980s, ceramics with ceramic materials as a medium made with the separation of inorganic ceramic film developed rapidly. Now it has been obtained a successful application in the petrochemical, food, biotechnology, medicine and other fields. Ceramic separation membrane is porous ceramic as the carrier (support), with microporous ceramic membrane as the filter layer of ceramic filter separation material. It is mainly based on the "physical screening" theory, according to a certain range of membrane pore infiltration of material molecules in different diameters of different permeability, the use of pressure difference as the driving force, is a small molecule material can be, macromolecules were interception, In order to achieve the separation between them ${ }^{[1]}$.

\section{Overview of Inorganic Ceramic Membranes}

\section{Structure and Advantages of Inorganic Ceramic Membrane.}

Ceramic film is also known as CT film, it is a kind of solid film. In terms of the general ceramic film, it is mainly porous ceramic as the carrier, that microporous ceramic membrane filter layer for the separation of the material. Ceramic membrane microfiltration element support and film are porous materials. These materials are usually prepared by bulk particle sintering. The inorganic ceramic membrane can be divided into symmetrical ceramic film and asymmetric ceramic film. One of the most commonly used is the asymmetric ceramic film; the main structure is divided into three layers, as shown in Figure 1. Compared with the traditional filter media, the ceramic microfiltration membrane has the advantages of uniform pore size, high filtration precision, thin film and no filter aid [1]. 


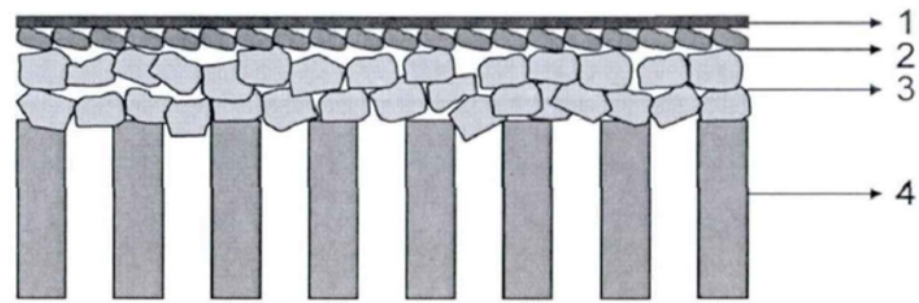

1-Improved separation layer (dense layer or microporous layer);

2-Separation layer (Aperture is 2-50nm); 3-middle layer (Aperture is $50-1000 \mathrm{~nm}$ ). 4- Large hole supvort laver (Averture is 1-15 $\mu \mathrm{m}$ )

Figure 1 the typical cross - section structure of ceramic membrane

From the emergence of ceramic film to the development so far, inorganic ceramic membrane separation technology's separation effect has been quite good, mainly due to inorganic ceramic film relative to other organic film has many advantages, including: (1) Acid, Alkali, resistant to organic solvents, chemical stability. This advantage makes the ceramic membrane can be well adapted to $\mathrm{pH}$ extremely high or very low material, stable to accept hot alkali or acid cleaning. (2) High temperature. It can operate generally at $400{ }^{\circ} \mathrm{C}$ high temperature, up to $1000{ }^{\circ} \mathrm{C}$. (3) Narrow distribution, high filtration efficiency (4) Long service life, low replacement cost. In many applications, inorganic ceramic membranes exhibit a long service life. Compared with the organic film, the replacement cost of the inorganic ceramic film can be greatly reduced. (5) Mechanical strength. The use of pressure up to $\mathrm{kPa}$ magnitude, and can be backwash, not easy to cause membrane blockage. (6) Anti-microbial ability, not with the role of microorganisms. (7) Simple operation, it is easy to save it ${ }^{[1,2]}$.

\section{Filtration Principle of Inorganic Ceramic Membrane.}

Inorganic ceramic membrane filtration theory can be broadly divided into two categories: (1) Sieving theory: due to a certain membrane pore size of the material through the infiltration of different diameter, resulting in different permeability. The raw material liquid in the membrane tube or membrane outside the flow of small molecules or liquid through the membrane, macromolecules and solid cannot pass through the membrane, to achieve the purpose of separation. (2) Adsorption: in the chemical bond, van der Waals force, electrostatic force, the pollutants are adsorbed on the membrane. In the process of passing the raw material liquid through the ceramic membrane, the effect of separating the contaminants is achieved ${ }^{[2,3]}$.

\section{Development of Inorganic Ceramic Membrane}

\section{Desalination pretreatment.}

In recent years, China's ceramic membrane technology applied to the desalination of seawater desalination research more and more in-depth. In the reverse osmosis process, the ceramic membrane as a pretreatment part, can remove the kicked suspended matter, macromolecular organic matter, bacteria and viruses, and the water quality and stability, can reduce the burden of reverse osmosis membrane, extend the service life of the membrane. So far the ceramic membrane applied to the desalination pretreatment unit has a lot of success stories, such as Zhou Shan desalination used in the ceramic membrane pretreatment. As of 2009, the daily treatment of water has reached $150 t$ water indicators to meet the requirements of the specification. In solving the water problem, the ceramic membrane as a pretreatment unit applied to the desalination pretreatment will play a more role ${ }^{[3,4]}$.

\section{Water supply treatment.}

In the water supply treatment, because the water index to meet the requirements, the application of ceramic membrane has gradually moved onto the table. However, because the ceramic membrane is usually used for high value-added products, the cost compared with the traditional process is higher, because it does not need to add chemical reagents, water quality and stability in Europe, the application of a longer time. In the domestic household ceramic membrane water purifier is also 
emerging, the process of filtration to retain useful minerals in the water, remove metal, rust, heavy metal ions. It doesn't produce secondary pollution. It developed prospect ${ }^{[5-7]}$.

\section{Industrial wastewater treatments.}

The development of the current society increased brings the serious environmental pollution. Ceramic membrane on the industrial wastewater in the oil wastewater, textile wastewater, printing and dyeing wastewater and so have a better removal effect, can be used as a pretreatment unit and two processing units to improve the efficiency of industrial wastewater treatment. As the inorganic ceramic membrane has a strong hydrophilic oleo phobic, the oil through the concentration is very low, high flux, long life, and the membrane pore size is relatively loose ${ }^{[6]}$. In 1991, the United States studied a ceramic microfiltration membrane for the preparation of water for oil field re-injection, and in Louisiana, the Gulf of Mexico on the sea and onshore oil field pilot, membrane velocity $0.5 \mathrm{~m} / \mathrm{s}$ to $4 \mathrm{~m} / \mathrm{s}$, the operating period of 24 hours to 73 hours, the membrane flux can be maintained at 1600L / $(\mathrm{m} 2 \cdot \mathrm{h})$ after the water oil less than $20 \mathrm{mg} / \mathrm{L}^{[5-7]}$.

\section{Domestic sewage treatments.}

China's experts to carry out a series of research, Chuanhong Xing membrane bioreactor treatment of domestic sewage were studied using a zirconia ultrafiltration membrane, cutting the relative molecular mass of 300000 . Studies have shown that membrane bioreactor treatment of domestic sewage the removal rate of COD and turbidity was more than $95 \%$ and $98 \%$ respectively. The removal rate of SS and Escherichia coli was $100 \%$, and the effluent quality was stable ${ }^{[8]}$. Xu Nong ${ }^{[9]}$ treat domestic Sewage by Tubular Ceramic Membrane Bioreactor. The results showed that the removal rate of COD was $99.5 \%$, the removal rate of ammonia nitrogen and suspended solids was $99.9 \%$ and $100 \%$, and all the effluent quality reached the standard of domestic water consumption.

\section{Prospect of Inorganic Ceramic Membrane}

At present, in addition to Japan and several other developed countries, the application of ceramic membrane technology is still mainly concentrated in the treatment of industrial wastewater. We can be seen in the ceramic film in recent years, the trend was a linear decline in the trend. Therefore, ceramic membrane in other areas still have a lot of room for development, such as ceramic film in the field of drinking water research has begun, but there is still a lot of room for research in the future can be in the following aspects of the ceramic membrane research: (1) Optimization of ceramic membrane preparation technology. Although the price of ceramic film in recent years showed a linear decline in the trend, but the ceramic membrane preparation costs are still high. Optimization of ceramic membrane preparation process is conducive to the promotion of ceramic membrane technology. (2) The development of new Nano-materials used as a ceramic membrane properties, is conducive to improving the ceramic membrane filtration accuracy and closure accuracy. (3) Study on Pretreatment Mechanism of Ceramic Membrane Pollution. At present, the study of membrane fouling in the world mainly lies in the organic film, and the research on inorganic membrane pollution is less. In the future, the membrane fouling model is combined with the pollutant stress situation, and the quantitative analysis can promote the development of new technology of water purification with ceramic film as the core ${ }^{[10]}$. (4) To optimize the combination of ceramic film as the core process. The current water quality changes are fluctuating, and the system integration of key technologies such as pre-film pretreatment, ceramic membrane treatment and water quality stabilization security is put forward to form the organizational process and technology system with ceramic film as the core. Only the optimization of the parameters of the combination process to ensure the efficient and stable operation of the system, ceramic membrane technology can make a great contribution to the promotion ${ }^{[11]}$. (5) The integrated treatment technology of ceramic membrane and membrane catalytic reactor, catalyst, organic ultra / micro / Nano filtration membrane and other processes still needs to be studied deeply, and the problem of brittleness and regeneration of ceramic membrane should be focused on to achieve stable operation. Need to focus on the characteristics of ceramic film, and organic film reasonable match, and jointly promote the healthy development of the membrane industry ${ }^{[11-12]}$. 


\section{Conclusions}

We can be seen something by the above review, inorganic ceramic membrane separation technology in recent years has been the community attention. Through in-depth study, inorganic ceramic membrane with its high temperature and high pressure, easy to clean, mechanical strength and other advantages have been widely recognized around the world. Experts and scholars around the world will be inorganic ceramic film applied to industrial waste water, domestic sewage, food, pharmaceutical and other fields, for us to create a more healthy, safe and environmentally friendly living environment.

\section{Acknowledgements}

This work was financially supported by the Shandong Provincial Key Research and Development Program (2016CYJS07A03-2), Shandong Provincial Natural Science Foundation, China (ZR2015EM021), Doctoral Foundation of University of Jinan (XBS1432) and partly supported by National Natural Science Foundation of China (51678276).

\section{References}

[1] ZHANG Xiaosai, NI Weihong. Development Status and Application of Ceramic Membrane [J]. Environmental Engineering. Vol. 31(2013), p. 108-112.

[2] CUI Jia, WANG Heli. Research Progress of Inorganic Ceramic Membrane in Water Treatment [J]. Industrial water treatment. Vol. 31(2011), p. 13-16.

[3] LIU Donglian. Summarization of Application of Inorganic Ceramic Membrane in Water Treatment [J]. Research \& development. Vol. 43(2017), p. 107.

[4] YAO Jilun, ZHANG Xing, ZHOU Zhen, et al. Review of Ceramic Membrane in Water Treatment[J]. Journal of Chongqing University of Technology (Natural Science). Vol. 30(2016), p. 69-74.

[5] LIANG Jianyou. Application of Ceramic Membrane in Industrial Water Treatment [J]. Guangdong Chemical Industry. Vol. 40(2013), p. 191-192.

[6] SUN Zihan, LI Si. Treatment of Industrial Wastewater by Inorganic Ceramic Membrane Separation Technology [J]. Contemporary chemical industry. Vol. 43(2014), p. 435-437.

[7] CAO Jingjie, DONG Xinfa. Advances in Application of Inorganic Ceramic Membrane Separation Technology [J]. Guangzhou Chemical Industry. Vol. 42(2014), p. 19-21.

[8] MAO Yanli, XIAO Xiaocun. Application Status and Development Trend of Inorganic Ceramic Membrane in Industrial Wastewater Treatment [J]. Coal Technology. Vol. 23(2004), p. 32-37.

[9] QING Weiwei, SONG Yonghui. Development and Application of Ceramic Membrane in Water Treatment [J]. Industrial water treatment. Vol. 31(2011), p. 15-19.

[10] CHEN Ruhai, FANG Zhendong. Application Status and Prospect of Inorganic Ceramic Membrane in Water Treatment [J]. Journal of Chongqing Polytechnical College. Vol. 19(2004), p. $1-4$.

[11] MENG Guangyao, CHEN Chusheng. Review and Prospect of Ceramic Membrane Separation Technology Development for 30 Years [J]. Membrane Science \& Technology. Vol. 31(2011), p. 86-95.

[12] CHENG Xiaoxiang, LIANG Heng. Development and Prospect of Ceramic Membrane Drinking Water Treatment Technology [J]. Journal of Harbin Institute of Technology. Vol. 48(2016), p. 1-10. 